\title{
Mode-locking behavior of Izhikevich neurons under periodic external forcing
}

\author{
AmirAli Farokhniaee ${ }^{1 *}$, Edward W Large ${ }^{1,2}$ \\ From 24th Annual Computational Neuroscience Meeting: CNS*2015 \\ Prague, Czech Republic. 18-23 July 2015
}

Many neurons in the auditory system of the brain must encode amplitude variations of a periodic signal. These neurons under periodic stimulation display rich dynamical states including mode-locking and chaotic responses [1]. Periodic stimuli such as sinusoidal waves and amplitude modulated (AM) sounds can lead to various forms of $n: m$ mode-locked states, similar to the mode-locking phenomenon in a LASER resonance cavity. Obtaining Arnold tongues provides useful insight into the organization of mode-locking behavior of neurons under periodic forcing. In this study we obtained the regions of existence of various mode-locked states on the frequency-amplitude plane, which are called Arnold tongues, for Izhikevich neurons (see Figure 1). This study is based on the model for neurons by Izhikevich (2003), which is a reduced model of a Hodgkin-Huxley neuron [2]. This model is much simpler in terms of the dimension of the coupled non-linear differential equations compared to other existing models, but excellent for generating the complex spiking patterns observed in real neurons [3]. Hence we can describe the construction of harmonic and sub-harmonic responses in the early processing stages of the auditory system, such as the auditory nerve and cochlear nucleus.

\section{Conclusion}

Different mode-locked regions that are shown in the Arnold tongues diagram are predictors of mode-locking of auditory system neurons to sound, which in turn predict the formation of harmonics and sub-harmonics of the sound in the brain.

* Correspondence: a.farok@uconn.edu

'Department of Physics, University of Connecticut, Storrs, CT, 06268, USA

Full list of author information is available at the end of the article

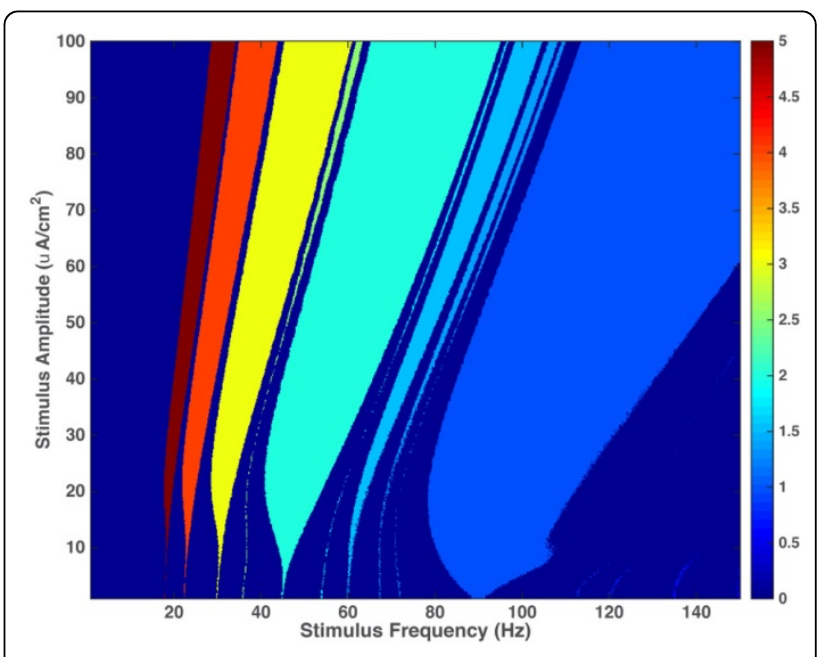

Figure 1 The Arnold tongues diagram for a Class 1 Izhikevich neuron driven by an external sinusoidal forcing. This plot represents the mode-locked regions as a function of the amplitude and frequency of this sinusoidal forcing. Each colored region represents a different phase-locked regime in terms of an integer ratio. Here, an $n: m$ ratio means the neuron produces $n$ action potentials in response to every $m$ cycles of the stimulus. For example, for stimulus amplitudes and frequencies corresponding to the yellow region, the neuron exhibits 3:1 mode-locking.

\section{Acknowledgements}

This work was supported by University of Connecticut College of Liberal Arts and Sciences.

\section{Authors' details}

'Department of Physics, University of Connecticut, Storrs, CT, 06268, USA.

${ }^{2}$ Department of Psychology, University of Connecticut, Storrs, CT, 06268, USA.

Published: 18 December 2015

\section{References}

1. St-Hilaire Martin, Longtin Andre: Comparison of Coding Capabilities of Type I and Type II Neurons. Journal of Computational Neuroscience 2004, 16:299-313. 
2. Izhikevich MEugene : Dynamical Systems in Neurosceince: The geometry of Excitability and Bursting. Cambridge, Massachusetts: The MIT Press; 2007.

3. Kim Youngtae: Identification of Dynamical States in Stimulated Izhikevich Neuron Models by Using a 0-1 Test. Journal of Korean Physical Society, 2010, 57(6):1363-1368.

doi:10.1186/1471-2202-16-S1-P140

Cite this article as: Farokhniaee and Large: Mode-locking behavior of Izhikevich neurons under periodic external forcing. BMC Neuroscience 2015 16(Suppl 1):P140.

Submit your next manuscript to BioMed Central and take full advantage of:

- Convenient online submission

- Thorough peer review

- No space constraints or color figure charges

- Immediate publication on acceptance

- Inclusion in PubMed, CAS, Scopus and Google Scholar

- Research which is freely available for redistribution

Submit your manuscript at www.biomedcentral.com/submit
Ciomed Central 